\title{
A latent class analysis of trauma based on a nationally representative sample of $U S$ adolescents
}

Gillian C. McChesney

Gary Adamson

Mark Shevlin

Gillian C. McChesney (corresponding author)

Room MB205

University of Ulster,

Northland Road,

Londonderry, 
Northern Ireland,

BT48 7JL

Email: mcchesney-g1@email.ulster.ac.uk

Tel: +442871885129

\title{
G. Adamson M. Shevlin
}

University of Ulster,

Northland Road,

Londonderry,

Northern Ireland,

BT48 7JL

Email: g.adamson@ulster.ac.uk

m.shevlin@ulster.ac.uk

\begin{abstract}
Purpose: Traumatic events in adolescence rarely occur in isolation. Multiple traumatic experiences are prevalent, diverse and a well-established risk factor for mental health disorders. The aim of this study was to explore and explain the heterogeneity in trauma profiles in a nationally representative sample of US adolescents. Method: Using latent class analysis, data on 10123 adolescents aged between 13 and 18 from the National Comorbidity Survey Adolescent Supplement (NCS-A) were examined. In addition, the relationships between the emergent classes and demographic and clinical variables were explored. Results: A four-class solution was the best fit of adolescent trauma patterns, with classes labelled as low risk, sexual assault risk, non-sexual risk and high risk. When compared to the low risk class, those in the other classes were significantly more likely not to live with either biological parent, display symptoms indicative of mood and anxiety disorders, and to have higher rates of disorder comorbidity. Conclusions: This provides evidence of four distinct groups of adolescents who have experienced a variety of traumas. Evidence demonstrates the increased risk of adolescents with a history of trauma meeting the diagnostic criteria for not only individual disorders, but for comorbidity across disorder categories.
\end{abstract}




\section{Keywords}

Adolescents, Traumatic events, Latent class analysis, Mental health disorders, Comorbidity

\section{Introduction}

Studies examining trauma rates and subsequent negative outcomes among nationally representative populations are common, but until recently few have focused on adolescent populations $[1,2,3]$. Evidence shows that by the time an individual reaches adolescence they are at risk of experiencing at least one traumatic event $[4,5]$, and when compared to adulthood, trauma exposure is at its peak during this time. This peak exposure time is reflected in research, with higher rates of post-traumatic stress disorder (PTSD) found in adolescents (13\%), compared to adults (7\%) [5].

Similarities exist between adolescent and adult trauma experiences, with events such as the death of loved ones, accidents, threats of violence, and witnessing injury or death, prevalent in both populations [1, 6]. That said, whilst trauma types may be similiarly prevalent, experiences and expressions of trauma are clearly not uniform across individuals and it is now well recognised that trauma experienced during adolescent years may create its own risks for negative psychological outcomes [7].

Research has explored such negative outcomes, showing various sequelae such as depression, personality disorders and PTSD [8-12]. However, most have focused on specific traumas, with sexual, physical, and emotional abuse well represented in the literature [8, 9, 13-15]. Research focusing on particular traumas can lead us to erroneously believe that such events occur in isolation, with some suggesting such studies to be methodologically limited $[16,17]$. It has been suggested that results from studies finding a link between single traumas and outcomes such as substance use, mood and anxiety disorders, are "tentative at best" [17] as exposure to other traumas are not considered. For example, some looking specifically at childhood sexual abuse do not consider the impact that other traumas can have on subsequent psychopathology [14], or look only at the impact of other adversities such as family environment [15].

Studies have now begun to investigate multiple trauma experiences and subsequent mental health. For example, in a study of 2,030 children examining trauma symptoms [18], multiple victimisation was 
common. Twenty-two percent were found to experience more than four victimisations (poly-victimisation) in the previous year alone (including sexual assault, physical abuse and witnessing assault to others). Evidence was also provided that poly-victimisation was highly predictive of poor psychological outcomes, with clinical levels of depressive and anxiety symptoms ( $80 \%$ and $86 \%$ respectively) evident in 10 to 17 year olds [18].

Evidence suggests that a traumatic event rarely occurs in isolation [18], and while adolescents can suffer the same traumas as adults [5], adolescent trauma patterns and mental health sequelae must be further examined. In order to do this recent studies have begun to apply statistical techniques such as latent class analysis (LCA), as a way of examining clusters of individuals within large and varied samples. For example, in a US sample of persons aged between 15 and 54, four trauma classes were identified; 'high risk', 'exposure to non-sexual adult interpersonal/non-interpersonal trauma', 'intermediate risk/sexual abuse', and, consisting of the highest proportion of individuals, 'low risk' [6]. Similar trauma patterns have also been identified using LCA in Danish school children age 13 to 15 [1], with the largest proportion also found to be in a 'low risk' trauma category. Such studies have helped to improve our understanding of the psychological outcomes of trauma by providing evidence that membership of high risk trauma classes can greatly increase the risk of disorders such as depression, psychosis, alcohol and drug dependence [6] and PTSD [1].

There are two main aims associated with this study. First, to determine if there are meaningful clusters of adolescents with similar trauma experiences across the full spectrum of traumatic events. Second, to explore the relationships between these homogeneous groups in terms of demographic variables, and the presence and comorbidity of clinical diagnoses encompassing a range of DSM-IV disorders [19], not previously used in research with latent trauma classes [1,6].

This study contributes to the literature in a number of ways. Firstly, previous studies that have examined trauma and mental health outcomes using the National Comorbidity Survey Adolescent Supplement (NCS-A) have done so with a smaller sub-sample $(\mathrm{N}=6,483)$ and using analytic techniques such as discrete time-survival analysis $[20,21]$. This study utilises the full NCS-A student sample $(\mathrm{N}=10,123)$, applying LCA in order to identify clusters of adolescents sharing similar trauma patterns. Secondly, a larger sample size is submitted to LCA than in previous studies utilising the same analysis tool $[1,6]$, with 
participants encompassing a wider adolescent age range [1,3]. Thirdly, this study looks not only at individual mental health diagnoses, but also examines comorbidity across disorders by looking at the three DSM-IV categories under which they fall (i.e. mood, anxiety, substance-use).

\section{Method}

\section{Sample}

This study used data from the NCS-A [22], a nationally representative epidemiological survey of 10,148 adolescents aged 13 to 18 years carried out in the United States (2001 to 2004). The NCS originated as a response to a nationally recognised need for information on predictors and patterns of mental health disorders amongst adults [23]. Beginning with the baseline NCS [24], the same respondents were later reinterviewed (NCS-2) [24], together with a new nationally representative household sample of 9,282 adults, the NCS Replication (NCS-R) [25] gathered further information on the course of mental health disorders. The latest NCS extension, the NCS-A, surveyed the prevalence, correlates and patterns of DSM-IV [19] mental health disorders amongst adolescents. The NCS-A is a dual-frame study, with adolescents recruited from a household sample $(\mathrm{N}=904)$ and from a nationally representative school sample $(\mathrm{N}=9244)$, with a combined adolescent response rate of $75.6 \%$. Also included in the household sample were a number of nonstudents, offering the possibility of comparing how they differed from students. However, as no precise inferences could be made from such a small sample of non-students $(\mathrm{N}=25)$, they are not included in any analysis [26]. Weighting for analysis, therefore, applies to the 10123 adolescent students. A full description of the NCS-A can be found elsewhere [26, 27]. Just over half the sample was female $(51.1 \%)$, and the mean age was 15.2 years.

\section{Measures}

The NCS-A [22] used the World Health Organisation Composite International Diagnostic Interview (WHO CIDI 3.0) [28] to obtain information about prevalence and correlates of mental health disorders, modified for use with adolescents [22]. Full details of the WHO CIDI are provided elsewhere [28].

This study assessed trauma exposure using the PTSD section of the NCS-A [22]. Traumatic experiences identified by the adolescents in the screening section were analysed $(\mathrm{N}=18)$, with the exception 
of the item covering other traumas. However, it was felt that the item concerning an undisclosed trauma was important to the analysis, in that whilst the exact nature of the trauma is unknown, the participant has chosen not to talk about it. This suggests that it elicited feelings of emotional pain, shame, or maybe even deviance, all of which have been linked to subsequent psychological symptoms [7]. These 18 traumas represented a comprehensive list of trauma experiences, and are consistent with the trauma categories required for a DSMIV diagnosis of PTSD; including combat, sexual and physical assault, disasters, serious car accidents, lifethreatening illnesses and witnessing serious injury or death, [19]. As suggested in previous research [29] this study focused solely on these trauma events that represent the greatest risk for poorer outcomes and not on what can be viewed as negative life events (parental divorce, being placed into care, etc.). An exception, however, is with the inclusion of the death of someone close.

Fifteen DSM-IV [19] disorders were assessed in the NCS-A, with evidence provided elsewhere of the good concordance between the WHO CIDI and clinical diagnoses of these disorders [30]. Previous research using statistical techniques such as LCA to identify trauma patterns have found associations with a number of disorders, including PTSD [1], substance use, non-affective psychosis, bi-polar disorder, and major depressive episodes [6]. In order to assess the impact of trauma across the spectrum of mental health diagnoses, and in a combination not previously used, two disorders were included from each of the mood, anxiety and substance-use categories of the DSM-IV [19]. They included lifetime prevalence of alcohol abuse, drug abuse, dysthymia, major depressive episode, generalised anxiety disorder (GAD) and PTSD. Demographic variables used in this study were gender, race, and living arrangements (living with both biological parents, one biological parent, or neither biological parent).

\section{Analyses}

Statistical analyses were conducted in three stages using Mplus version 7 [31]. First, LCA was employed to determine if there were meaningful groups sharing similar patterns of trauma experience. In order to account for the complex survey sampling of the data, all analysis included sampling weights. The fit of five models (two-class through to six-class) was assessed using the Akaike Information Criterion (AIC) [32], the Bayesian Information Criterion (BIC) [33], and the sample size-adjusted Bayesian Information Criterion (ssaBIC) [34]. Given the complex survey data a suitable alternative to the bootstrap likelihood 
ratio test (BLRT) to compare models [35] is the Lo-Mendell-Rubin adjusted likelihood ratio test (LMR) [36]. Entropy measures were used to determine how accurately participants were classified, with higher values (ranging from 0 to 1) indicating better classification [37]. Second, gender, race, and living arrangements were added to the model in order to explore which variables significantly predicted class membership. Finally, the emergent latent classes were assessed for any associations with the six clinical variables, and with possible comorbidity amongst the clinical categories.

\section{Results}

Table 1 shows the frequencies of trauma exposure, together with results from bivariate chi-square tests of independence between trauma type and gender. The most common trauma experienced was the death of a loved one, followed by witnessing someone being injured or killed, exposure to a major disaster, and trauma experienced by a loved one. The least prevalent were exposure to a poisonous chemical, living in a terror situation, and being beaten by either parents or a romantic partner. Chi-square tests were statistically significant for a number of the traumas, with expected frequencies indicating that females were more likely to report the death of someone close, trauma to someone close, witnessing fights at home, an undisclosed significant trauma, stalked, sexual assault, rape, and being beaten by a romantic partner. Whereas males were more likely to report witnessing injury/death, a major disaster, life threatening car accident, other threatening accident, being mugged/threatened with a weapon, serious illness, beaten (other) and exposure to a poisonous chemical.

Less than half (38.2\%) of the participants indicated that they had not experienced any trauma, $28 \%$ had experienced one, $16 \%$ two, $8.1 \%$ three, $4.2 \%$ four, with $5.4 \%$ having experienced five or more traumas. This percentage breakdown was also repeated within the female and male populations, with less than half (38.3\% of females and $38.1 \%$ of males) reporting no traumas, and close to the overall $5.4 \%(5.4 \%$ of females and $5.7 \%$ of males) reporting five or more traumas.

Table 2 outlines the fit indices for the LCA. The LMR becomes non-significant with the five-class solution $(\mathrm{p}=.72)$ suggesting that the four-class model should be accepted. The AIC, BIC and ssaBIC were lower for the four-class solution, than for the previous class solutions, further supporting acceptance of this 
model. The entropy value (.75) is at an acceptable level, with 0.80 considered high and 0.60 medium [38]. The latent class profile plot is shown in Figure 1.

Class $1(1.3 \%)$, was characterized by adolescents displaying relatively high probabilities of experiencing each of the 18 traumas (the exception being exposure to a poisonous chemical or substance, living in a place of terror, and being beaten by a romantic partner). This class was labelled high risk. Class 2 (4.6\%), was characterized by adolescents displaying relatively high probabilities of experiencing witnessing fights at home, and a loved one experiencing a stressful or life-threatening situation. Class 2 also displayed comparatively higher probabilities of experiencing sexual assault and rape. This class was labelled the sexual assault class. Class 3 (15.6\%), was characterized by adolescents displaying relatively higher probabilities of endorsing witnessing injury or death, experiencing a major disaster, having an accident other than in a car, and being beaten by someone other than a parent or partner. With increased risk of interpersonal and non-interpersonal trauma experiences, all of which are non-sexual, this class was labelled the non-sexual trauma class. Class 4 (78.5\%), was characterized by adolescents displaying consistently lower probabilities of endorsing any of the traumas (with the exception of death of a loved one, which had high endorsement across all classes). This class, labelled the low risk class, was considered the baseline in further analyses.

Class membership was used as the dependent variable in a multinomial logistic regression model, used to analyse associations between the classes and demographic variables. Variables representing gender, race, and living arrangements were entered as predictors. Table 3 shows the odds ratios associated with each predictor and the trauma class percentages for each of the sociodemographic variables. Results indicate that, when compared to the low risk group, females have a significantly increased probability of being in the sexual assault group $(\mathrm{OR}=8.15, \mathrm{p}<0.001)$ and a significantly reduced likelihood of being in the nonsexual group $(\mathrm{OR}=0.58, \mathrm{p}<0.001)$. Class 3 showed slightly increased probabilities of having adolescents who are of non-white descent. This group, when compared to the low risk trauma group, were almost twice as likely to be hispanic $(\mathrm{OR}=1.71, \mathrm{p}<0.001)$, or black $(\mathrm{OR}=1.73, \mathrm{p}<0.001)$ when compared to white adolescents; with Class 2 showing a significantly reduced likelihood of being black $(\mathrm{OR}=0.69, \mathrm{p}<0.05)$. All classes displayed significant increased probabilities of living with less than both biological parents when 
compared to the low risk group. Those living with neither biological parent being at significantly increased odds of being in the high risk class $(\mathrm{OR}=14.49, \mathrm{p}<0.001)$.

Logistic regression investigated the relationship between the latent trauma classes and clinical disorders. The latent classes were dummy coded, using the low risk class as the reference category, and were then entered to a logistic regression model as independent variables, with the clinical disorders as dependent variables. The high risk, sexual assault, and non-sexual classes were significant predictors when compared to the baseline class. Suggesting a significantly increased likelihood of a clinical diagnosis among the three trauma classes when compared to the low risk group. Results displayed in Table 4 show higher odds of any of the clinical disorders among the high risk class, suggesting that those in this class were at the highest risk for all disorders.

It is evident when looking at the percentages within the trauma classes of those who meet the criteria for each disorder that some degree of comorbidity across disorders is probable. In order to investigate this, further regression analysis determined the relationship between the trauma latent classes and disorder comorbidity (i.e. the presence of a substance use disorder along with a mood disorder). Table 5 shows the three trauma classes to be significant predictors of comorbidity across the disorder categories. The highest likelihood of comorbidity between two disorder categories across the three trauma classes was found with a substance use disorder (alcohol abuse/drug abuse) appearing alongside an anxiety disorder (generalised anxiety disorder/PTSD). The probability of comorbidity across all three DSM-IV categories is also significant within the trauma classes, with the high risk class being over 100 times as likely to suffer all disorder categories comorbidly $(\mathrm{OR}=109.74, \mathrm{p}<.001)$ when compared to those in the low risk trauma group.

\section{Discussion}

The main aims of this study were to explore trauma profiles within a large sample of adolescents, and to then investigate associations between trauma classes, clinical disorders and comorbidity. Results showed that the death of a loved one was the most commonly reported trauma, followed by witnessing injury or death. Living in a terror situation, and being beaten (by parents or partner) were least reported. Evidence 
was also provided that trauma exposure does not occur in isolation, with over $33 \%$ reporting two or more trauma experiences.

Results showed that adolescent trauma experiences could be explained by a number of homogenous sub-groups. The emergence of four latent classes, where low risk and high risk profiles are evident, shows consistency with previous trauma research $[1,6]$. The four classes in this study were labelled high risk (class 1), sexual assault risk (class 2), exposure to non-sexual trauma (class 3), and low risk (class 4). Just over $90 \%$ of participants were to be found in classes 3 and 4 . Class 4 represented participants who had very low probabilities of experiencing trauma, with the exception of the death of a loved one, common to all four classes. Class 3 represented a group that had increased probabilities of experiencing non-sexual interpersonal, and non-interpersonal traumas. Whilst displaying probabilities of experiencing most traumas at levels somewhere between the previous two groups, members of class 2 displayed probability levels of experiencing sexual assault and rape similar to those in the high risk group. This group also displayed higher probabilities of having experienced an undisclosed trauma. This supports the view that such undisclosed traumas may be linked to feelings of shame or deviance; feelings previously shown to be associated with sexually related traumatic experiences [7]. The group representing the smallest proportion of participants was class 1 , displaying relatively high probabilities of experiencing most traumas, particularly those involving serious interpersonal violence, or witnessing such violence perpetrated against others. The small size of this high risk class is meaningful in that whilst a large proportion of this adolescent population have suffered some form of trauma(s), it is only a few who have suffered multiple trauma events during their childhood to adolescent years.

As with previous research, gender differences within trauma classes have been supported [6]. Females were more likely to experience trauma of a sexual nature, but less likely to be exposed to non-sexual trauma. Previous research has found that ethnic minorities are less likely to be exposed to any potentially traumatic event when compared to whites [39]. It was therefore not unexpected that overall being of a minority ethnicity did not significantly predict trauma exposure in two of the three classes. However, it was significant that those of black ethnicity were less likely than whites to be in the sexual assault risk group, supporting previous research where ethnic minorities display lower risks for experiencing unwanted sex [39]. 
Trauma events such as witnessing violence, which are typical of the profile of the non-sexual risk class in this study, are more likely to be experienced by ethnic minority groups [39]; a finding supported here with non-whites, being more likely to be in this class when compared with the low risk class. Living in a household where neither biological parent was present was found to be highly indicative of high risk trauma. Previous research indicates that living with both biologial parents is more beneficial to adolescents [40], with not living with both parents shown to be associated with a higher total number of traumatic events, including physical, and sexual abuse, serious accidents, and threats of beatings [41].

Consistent with previous research [6], results indicate a significantly increased likelihood of a substance use/mood/anxiety disorder diagnosis across all classes when compared to the low risk group, and that disorder comorbidity is strongly associated with trauma events. It is difficult to compare the findings of this study to previous research due to the small body of work exploring latent trauma classes and mental health outcomes. That said, evidence from previous research can still be cited here for a number of reasons. First, research has consistently shown females to be more at risk of developing anxiety disorders, particularly as a result of sexually related trauma [42], and for such females to then be uniquely associated with PTSD, occurring comorbidly with GAD [43]. Such findings are supported within this study, with those in the sexual assault risk group being over eight times as likely to be female, over 26 times as likely to have a diagnosis of PTSD, and just over three and a half times as likely to have GAD. Second, previous research has also found anxiety disorders to be associated with emotional traumas, that is, those traumas that do not stem from a physical act e.g. being assaulted, or being in an accident [44]. However, within this study those in the high risk group who were at the highest risk of the anxiety disorders examined, reported a wide variety of physical based traumas, ranging from being mugged to witnessing fights at home.

With the exception of PTSD, where significant and high rates of association are to be expected between it and trauma events, risk of substance use disorders was significantly high in all trauma classes. This is consistent with previous research where substance abuse disorders are highly prevalent amongst adolescents, with lifetime prevalence rates ranging from $11.4 \%$ [45] to as high as $32.4 \%$ [46]. Research shows adolescents with a trauma history are more likely to report and be treated for substance abuse, than 
those who have suffered no trauma $[47,48]$, with a strong correlation existing between PTSD and substance abuse [49].

Adolescents in all trauma groups had high probabilities of the presence of a mood disorder (dysthymia and major depressive episode). Research has unequivocally shown depression to be one of the most common symptoms reported by survivors of childhood trauma, particularly those who experienced sexual abuse [50]. Here, two extremes of mood disorders were explored; a mood 'episode' where a depressed mood is present for at least two weeks (major depressive episode), and a chronically depressed disorder where the adolescents mood is described as "sad", with symptoms present more days than not for at least two years (dysthymia) [19]. These two mood disorders showed significant associations with all trauma classes, with those in the high risk group over eleven times as likely to have had diagnoses of both dysthymia and a major depressive episode, when compared to the low risk class.

As mentioned above, it was to be expected that those suffering trauma would show increased probabilities of a PTSD diagnosis. Consistent with previous research [1] the trauma classes displayed significantly higher probabilities of a PTSD diagnosis when compared to the low risk class. Further supporting previous work, with those in the sexual assault class being over 26 times as likely to suffer PTSD, adolescent PTSD has been shown to be related to trauma type. For example, Nooner et al [7] demonstrated that $57 \%$ of those suffering sexually related trauma had PTSD, compared to just $10 \%$ of those who lived through a natural disaster [7]. Also consistent with previous research is the finding that PTSD is more likely to occur comorbidly with other clinical disorders, with one study finding $52 \%$ of their adolescent female population displaying comorbid symptoms of PTSD and major depressive episode [4]. This study provided evidence that adolescents in the high risk trauma group were more likely to be female, more likely to live with neither biological parent, and more likely to have a PTSD diagnosis. All findings consistent with previous research where PTSD has been found to be twice as likely to develop in females, those with less social support, and those who suffer repeated traumas [7].

This study further examined the association between trauma profiles and clincical disorders by looking at the presence of disorder category comorbidity amongst the latent classes. High rates of comorbidity were found across the trauma classes when compared to the low risk class for substance use 
disorders appearing comorbidly with either a mood or anxiety disorder, and a mood disorder appearing alongside an anxiety disorder. Findings consistent with previous research, where the psychological sequealae of childhood trauma has shown the comorbidity of anxiety, mood [51], and substance use disorders $[52,53]$. A key finding of this study was that the highest rates of comorbidity were present for substance use and anxiety disorders across the three trauma classes, with those in the high risk class almost 40 times as likely to meet the diagnostic criteria for a substance use and anxiety disorder. Despite the fact that it is hard to compare this research to past work, in that few studies have examined clinical disorders with reference to latent trauma classes, previous research has found substance use disorders to frequently appear comorbidly with other clinical disorders, particularly mood and anxiety disorder [54]. Whilst previous work has shown that substance use disorders are more likely to appear comorbidly with mood disorders [55], other work has found evidence of high rates of substance use and anxiety disorder comorbidity, especially amongst females [56] and particularly with PTSD [57]. Previous research has also found evidence that over half (57.5\%) of those with a substance use disorder occurring comorbidly with an anxiety disorder, particularly PTSD, were more likely to have had their most upsetting traumatic experience before the onset of either disorder [58]. Future work could further explore this issue by examining the temporal ordering of trauma events and onset of clinical disorders.

This study set out to identify clusters of adolescents who share similar patterns of trauma experience and may help towards a fuller understanding of adolescent trauma typology. With that in mind, however, a few limitations must be highlighted. The main trauma categories used here were found within the PTSD section used in the NCS-A $[22,28]$. It has previously been found that asking more detailed questions about traumatic events can lead to more accurate exposure reports [57]. This study may have benefited with more detailed questions, with particular focus on sexual assault. The PTSD section covers only two categories rape and any other sexual assault or molestation, with no items exploring the relationship to the perpetrator. Future NCS-A analysis could explore whether sexual abuse takes place within a family context by examining the frequency of sexual assault/rape events, a method supported by previous research [58, 59].

This study has explored the variation in trauma profiles by looking at a range of trauma experiences occurring in adolescence. The contribution this study makes to the literature lies in the reasons as to why it 
is not directly comparable to previous research. First, this study uses a sample size that is much larger than in previous trauma studies using LCA $[1,6]$. Second, an age range encompassing more of the teenage ages strongly associated with adolescence is used [1]. And finally, whilst there are a core set of trauma events that are consistent across studies such as the death of a loved one, sexual assault, rape, and life-threatening accidents, this study has used a larger range of trauma events that fall under the DSM-IV [19] criteria for PTSD diagnoses. These differences notwithstanding, heterogeneity in trauma experiences was evident through the identification of four homogenous sub-groups of individuals who share similar trauma profiles. The emergence of four classes is consistent with previous studies exploring trauma experiences using latent class analysis $[1,6,19]$, showing that adolescents are not only exposed to individual events but to a range of trauma experiences. 


\section{Acknowledgements}

This study was funded as part of a PhD studentship through a Department of Education and Learning (DEL) Northern Ireland award to the corresponding author. DEL had no further role in study design; data analysis; report writing; or in the decision to submit the paper for publication.

On behalf of all authors, the corresponding author states that there is no conflict of interest.

\section{References}

1. Shevlin, M., \& Elklit, A. (2008). A latent class analysis of adolescent adverse life events based on a Danish national youth probability sample. Nord J Psychiatry, 62:218-224.

2. Elklit, A., \& Petersen, T. (2008). Exposure to traumatic events among adolescents in four nations. Torture, 18(1):2-11.

3. Petersen, T., Elklit, A., \& Olesen, J. G. (2010). Victimization and PTSD in a Faroese youth totalpopulation sample. Scand JmPsychol, 51(1):56-62.

4. Macdonald, A., Danielson, C. K., Resnick, H. S., Saunders, B. E., \& Kilpatrick, D. G. (2010). PTSD and comorbid disorders in a representative sample of adolescents: The risk associated with multiple exposures to potentially traumatic events. Child Abuse Negl, 34:773-783.

5. Breslau, N., Wilcox, H. C., Storr, C. L., Lucia, V. C., \& Anthony, J. C. (2004). Trauma exposure and posttraumatic stress disorder: A study of youths in Urban America. J Urban Health, 81:530-544.

6. Houston, J. E., Shevlin, M., Adamson, G., \& Murphy, J. (2011). A person-centred approach to modelling population experiences of trauma and mental illness. Soc Psychiatry Psychiatr Epidemiol, 46:149-157.

7. Nooner, K. B., Linares, L. O., Batinjane, J., Kramer, R. A., Silva, R., \& Cloitre, M. (2012). Factors Related to Posttraumatic Stress Disorder in Adolescence. Trauma Violence Abuse, 13(3):153-166.

8. Mullen, P. E., Walton, V. A., Romans-Clarkson, S. E., \& Herbison, P. (1988). Impact of Sexual and Physical Abuse on Women's Mental Health. Lancet, 331(8590):841-845.

9. Gibb, B. E., Chelminski, I., \& Zimmerman, M. (2007). Childhood emotional, physical and sexual abuse, and diagnoses of depressive and anxiety disorders in adult psychiatric outpatients. Depress Anxiety, 24(4):256-263.

10. Carr, S., \& Francis, A. (2009). Childhood maltreatment and adult personality disorder symptoms in a non-clinical sample. Aust Psychol, 44(3):146-155.

11. Green, J. G., McLaughlin, K. A., Berglund, P. A., Gruber, M. J., Sampson, N. A., Zaslavsky, A. M., et al. (2010). Childhood adversities and adult psychopathology in the National Comorbidity Survey Replication (NCS-R) I: Associations with first onset of DSM-IV Disorders. Arch Gen Psychiatry, 67(2):113-133.

12. Guadiano, B. A., \& Zimmerman, M. (2010). The relationship between childhood trauma history and the psychotic subtype of major depression. Acta Psychiatr Scand, 121(6):462-470. 
13. Horwitz, A. V., Widom, C. S., McLaughlin, J., \& White, H. R. (2001). The Impact of Childhood Abuse and Neglect on Adult Mental Health: A Prospective Study. J Health Soc Behav, 42(4):184201.

14. Cutajar, M.C., Mullen, P.E., Ogloff, J.R.P., Thomas, S.D., Wells, D.L. \& Spataro, J. (2010) Psychopathology in a large cohort of sexually abused children followed up to 43 years. Child Abuse Neglect, 34:813-822

15. Perez-Fuentes, G., Olfson, M., Villegas, L., Morcillo, C., Wang, S. \& Blanco, C. (2013) Prevalence and correlates of child sexual abuse: a national study. Compr Psychiat, 54:16-27

16. Edwards, V. J., Holden, G. W., Felitti, V. J., \& Anda, R. F. (2003). Relationship between multiple forms of childhood maltreatment and adult mental health in community respondents: Results from the adverse childhood experiences study. Am J Psychiatry, 160:1453-1460.

17. Green, B. L., Goodman, L. A., Krupnick, J. L., Corcoran, C. B., Petty, R. M., Stockton, P., et al. (2000). Outcomes of Single Versus Multiple Trauma Exposure in a Screening Sample. J Trauma Stress, 13(2): 271-286.

18. Finkelhor, D., Ormrod, R. K., \& Turner, H. A. (2007). Poly-victimization: A neglected component in child victimization. Child Abuse Negl, 31:7-26.

19. American Psychiatric Association. (2000). Diagnostic and Statistical Manual of Mental Disorders $D S M-I V-T R$ (4th ed). Washington, DC: American Psychiatric Association.

20. McLaughlin, K.A., Grief Green, J., Gruber, M.J., Sampson, N.A., Zaslavsky, A.M. \& Kessler, R.C. (2012). Childhood Adversities and First Onset of Psychiatric Disorders in a National Sample of US Adolescents. Arch Gen Psychiatry 69(11): 1151-1160

21. McLaughlin, K.A., Koenen, K.C., Hill, E.D., Petukhova, M., Sampson, N.A., Zaslavsky, A.M., Kessler, R.C. (2013). Trauma Exposure and Posttraumatic Stress Disorder in a National Sample of Adolescents. J Am Acad Child Psy 52(8):815-830

22. Merikangas, K. R., Avenevoli, S., Costello, E. J., Koretz, D., \& Kessler, R. C. (2009). The National Comorbidity Survey Adolescent Supplement (NCS-A): I. Background and Measures. J Am Acad Child Adolesc Psychiatry, 48(4): 367-369.

23. Grob, G. N. (2005). Public Policy and Mental Illnesses: Jimmy Carter's Presidential Commission on Mental Health. The Milbank Quarterly, 83 (3), 425-456.

24. Kessler, R. C. (2011). The National Comorbidity Survey (NCS) and its Extensions. In M. T. Tsuang, M. Tohen, \& P. Jones (Eds.), Textbook of Psychiatric Epidemiology (3rd ed., p. Chp 14). Chichester, United Kingdom: John Wiley \& Sons.

25. Kessler, R. C., \& Merikangas, K. R. (2004). The National Comorbidity Survey Replication (NCS-R): background and aims. Int J Meth Psych Res, 13:60-68.

26. Kessler, R. C., Avenevoli, E., Costello, E. J., Green, J. G., Gruber, M. J., Heeringa, S., et al. (2009a). Design and field procedures in the US National Comorbidity Survey Replication Adolescent Supplement (NCS-A). Int J Meth Psych Res, 18(2): 69-83. 
27. Kessler, R. C., Avenevoli, S., Costello, E. J., Green, J. G., Gruber, M. J., Heeringa, S., et al. (2009b). National Comorbidity Survey Replication Adolescent Supplement (NCS-A): II. Overview and design. J Am Acad Child Adolesc Psychiatry, 48:380-385.

28. Kessler, R. C., \& Ustun, T. B. (2004). The World Mental Health (WMH) Survey Iniative Version of the World Health Organization (WHO) Composite International Diagnositc Interview (CIDI). Int $J$ Meth Psych Res, 13(2):93-121.

29. Hovens , J. G., Wiersma, J. E., Giltay, E. J., Van Oppen, P., Spinhoven, P., Penninx, B. W., et al. (2010). Childhood life events and childhood trauma in adult patients with depressive anxiety and comorbid disorders vs controls. Acta Psychiatr Scand, 122:66-74.

30. Kessler, R. C., Avenevoli, S., Green, J. G., Gruber, M. J., Guyer, M., He, Y., et al. (2009c). National Comorbidity Survey Replication Adolescent Supplement (NCS-A): III. Concordance of DSMIV/CIDI diagnoses with clinical reassessments. J Am Acad Child Adolesc Psychiatry, 48:386-399.

31. Muthen, L. K., \& Muthen, B. O. (2012). Mplus User's Guide (7th ed). Los Angeles: California.

32. Akaike, H. (1987). Factor-analysis and Aic. Psychometrika, 52:317-332.

33. Scwartz, G. (1978). Estimating the dimension of a model. Ann Stat, 6:461-464.

34. Sclove, S. L. (1987). Application of model-selection criteria to some problems in multivariateanalysis. Psychometrika, 52:333-343.

35. Yang, C-C. (2006). Evaluating latent class analysis models in qualitative phenotype identification. Computational Statistics and Data Analysis 50:1090-1104.

36. Lo, Y., Mendell, N. R., \& Rubin, D. B. (2001). Testing the number of components in a normal mixture. Biometrika, 88(3):767-778.

37. Celeux, G. \& Soromenho, G. (1996). An entropy criterion for assessing the number of clusters in a mixture model. Journal Classif., 13:195-212

38. Wang, J. \& Wang, X. (2012) Structural Equation Modeling: Applications Using Mplus. John Wiley \& Son: Higher Education Press.

39. Roberts, A. L., Gilman, S. E., Breslau, J., Breslau, N., \& Koenen, K. C. (2011). Race/ethnic differences in exposure to traumatic events, development of post-traumatic stress disorder, and treatment-seeking for post-traumatic stress disorder in the United States. Psyhcol Med, 41(1): 71-83.

40. Manning, W. D., \& Lamb, K. A. (2004). Adolescent Well-Being in Cohabiting, Married, and SingleParent Families. J Marriage Fam, 65(4):876-893.

41. Elklit, A. (2002). Victimization and PTSD in a Danish National Youth Probability Sample. J Am Acad Child Adolesc Psychiatry, 41(2):174-181.

42. Stein, M. B., Walker, J. R., Anderson, G., Hazen, A. L., Ross, C. A., Eldridge, G., et al. (1996). Childhood Physical and Sexual Abuse in Patients with Anxiety Disorders and in a Community Sample. Am J Psychiatry, 153(2):275-277. 
43. Cougle, J. R., Timpano, K. R., Sachs-Ericsson, N., Keough, M. E., \& Riccardi, C. J. (2010). Examing the unique relationships between anxiety disorders and childhood physical and sexual abuse in the National Comorbidity Survey-Replication. Psychiatry Res, 177:150-155.

44. Lochner, C., Seedat, S., Allgulander, C., Kidd, M., Stein, D., \& Gerdner, A. (2010). Childhood trauma in adults with social anxiety disorder and panic disorder: a cross-national study. Afr J Psychiatry, 13(5):376-381.

45. Safren, S. A., Gershuny, B. S., Marzol, P., Otto, M. W., \& Pollack, M. H. (2002). History of Childhood Abuse in Panic Disorder, Social Phobia, and Generalized Anziety Disorder. J Nerv Ment Dis, 190(7):453-456.

46. Hasin, D.S., Stinson, F.S., Ogburn, E. \& Grant, B.F. (2007). Prevalence, Correlates, Disability, and Comorbidity of DSM-IV Alcohol Abuse and Dependence in the United States: Results From the National Epidemiologic Survey on Alcohol and Related Conditions. Arch Gen Psychiatry, 64(7): 830842.

47. Compton, W.M., Thomas, Y.F., Stinson, F.S. \& Grant, B.F. (2007). Prevalence, Correlates, Disability, and Comorbidity of DSM-IV Drug Abuse and Dependence in the United States: Results From the National Epidemiologic Survey on Alcohol and Related Conditions. Arch Gen Psychiatry, 64: 566576.

48. Kilpatrick, D. G., Saunders, B. E., \& Smith, D. W. (2003). Youth Victimization: Prevalence and Implications. National Institute of Justice, US Department of Justice. Washington DC: Office of Justice Programs.

49. Funk, R.R., Mcdermeit, M., Godley, S.H. \& Adams, L. (2003). Maltreatment Issues by Level of Adolescent Substance Abuse Treatment: The Extent of the Problem at Intake and Relationship to Early Outcomes. Child Maltreat 8(1): 36-45

50. Giaconia, R.M., Reinherz, H.Z., Hauf, A.C., Paradis, A.D., Wasserman, M.S. \& Langhammer, D.M. (2000). Comorbidity of Substance Use and Post-Traumatic Stress Disorders in a Community Sample of Adolescents. American Journal of Orthopsychiatry 70(2): 253-262.

51. Everett, B., \& Gallop, R. (2001). The Link Between Childhood Trauma and Mental Illness: Effective Interventions for Mental Health Professionals. California: Sage Publications Inc.

52. Suliman, S., Mkabile, S. G., Fincham, D. S., Ahmed, R., Stein, D. J., \& Seedat, S. (2009). Cumulative effect of multiple trauma on symptoms of posttraumatic stress disorder, anxiety and depression in adolescents. Compr Psychiatry, 50:121-127.

53. Merikangas, K. R., He, J.-P., Brody, D., Fisher, P. W., Bourdon, K., \& Koretz, D. S. (2010). Prevalence and Treatment of Mental Disorders Among US Children in the 2001-2004 NHANES. Pediatrics, 125 (1):75-81.

54. Meltzer, H., Bebbington, P., Brugha, T., Farrell, M., Jenkins, R. \& Lewis, G. (2000). The reluctance to seek treatment for neurotic disorders J of Mental Health 9(3): 319-327

55. Tishelman, A. C., \& Geffner, R. (2011). Child and Adolescent Trauma across the Spectrum of Experience: Research and Clinical Interventions. J Child Adolesc Trauma, 4:1-7. 
56. Jonsson, U., Bohman, H., von Knorring, L., Olsson, G., Paaren, A., \& von Knorring, A.-L. (2011). Mental health outcome of long term and episodic adolescent depression: 15-year follow-up of a community sample. J Affect Disord, 130(3):395-404.

57. Williams, L. M., Siegel, J. A., \& Pomeroy, J. J. (2000). Validity of women's self-reports of documented child abuse. In S. Stone, \& J. S. Turkkan, The science of self-report: Implications for research and practice. Malwah, NJ: Erlbaum.

58. Molnar, B.E., Buka, S.L. \& Kessler, R.C. (2001). Child sexual abuse and subsequent psychopathology. Results from the National Comorbidity Survey. Am J Public Health 91: 753-760.

59. Lee, S., Tsang, A., von Korff, M., de Graaf, R., Benjet, C., Haro, J.M., Angermeyer, M., Demyttenaere, K., de Girolamo, G., Gasquet, I., Merikangas, K., Posada-Villa, J., Takeshima, T. \& Kessler, R.C. (2009). Association of headache with childhood adversity and mental disorder: crossnational study. BJP 194:111-116.

Table Frequency of exposure to trauma and partition by gender 
Total Sample Females Males

Trauma

$\mathbf{N}=10,123(\%) \quad \mathrm{N}=5,170(\%) \quad \mathrm{N}=4,953(\%) \quad \chi^{2}$ 


\begin{tabular}{|c|c|c|c|c|}
\hline Death of someone close & $3060(30.2)$ & $1717(33.2)$ & $1343(27.1)$ & $44.57 * * *$ \\
\hline Witness injury/death & $1309(12.9)$ & $557(10.8)$ & $752(15.2)$ & $43.63 * * *$ \\
\hline Major disaster & $1233(12.2)$ & $590(11.4)$ & $643(13.0)$ & $5.81 *$ \\
\hline Trauma to someone close & $1008(10.0)$ & $658(12.7)$ & $350(7.1)$ & $89.96 * * *$ \\
\hline Witness fights (at home) & $831(8.2)$ & $484(9.4)$ & $347(7.0)$ & $18.58 * * *$ \\
\hline Life-threatening accident (car) & $820(8.1)$ & $387(7.5)$ & $433(8.7)$ & $5.37 *$ \\
\hline $\begin{array}{l}\text { Life-threatening accident } \\
\text { (other) }\end{array}$ & $818(8.1)$ & $319(6.2)$ & $499(10.1)$ & $51.92 * * *$ \\
\hline $\begin{array}{l}\text { Mugged/threatened with } \\
\text { weapon }\end{array}$ & $791(7.8)$ & $197(3.8)$ & $594(12.0)$ & $235.12 * * *$ \\
\hline Serious Illness & $656(6.5)$ & $300(5.8)$ & $356(7.2)$ & $8.02 * *$ \\
\hline $\begin{array}{l}\text { Significant trauma } \\
\text { (undisclosed) }\end{array}$ & $609(6.0)$ & $374(7.2)$ & $235(4.7)$ & $27.78 * * *$ \\
\hline Beaten (other) & $518(5.1)$ & $146(2.8)$ & $372(7.5)$ & $114.49 * * *$ \\
\hline Stalked & $498(4.9)$ & $383(7.4)$ & $115(2.3)$ & $139.85 * * *$ \\
\hline Sexual assault & $382(3.8)$ & $334(6.5)$ & $48(1.0)$ & $210.17 * * *$ \\
\hline Rape & $301(3.0)$ & $282(5.5)$ & $19(0.4)$ & $225.62 * * *$ \\
\hline $\begin{array}{l}\text { Exposure to poisonous } \\
\text { chemical }\end{array}$ & $276(2.7)$ & $86(1.7)$ & $190(3.8)$ & $45.00 * * *$ \\
\hline Lived in terror situation & $233(2.3)$ & $119(2.3)$ & $114(2.3)$ & 0.01 \\
\hline Beaten (by parents) & $206(2.0)$ & $116(2.2)$ & $90(1.8)$ & 2.31 \\
\hline Beaten (by romantic partner) & $87(0.9)$ & $37(1.3)$ & $20(0.4)$ & $23.62 * * *$ \\
\hline \multicolumn{5}{|l|}{ Number of Traumas } \\
\hline $\mathbf{0}$ & $3865(38.2)$ & $1979(38.3)$ & $1886(38.1)$ & \\
\hline 1 & $2839(28.0)$ & $1419(27.4)$ & $1420(28.7)$ & \\
\hline 2 & $1615(16.0)$ & $834(16.1)$ & $781(15.8)$ & \\
\hline 3 & $824(8.1)$ & $430(8.3)$ & $394(8.0)$ & \\
\hline 4 & $421(4.2)$ & $233(4.5)$ & $188(3.8)$ & \\
\hline $5+$ & $559(5.4)$ & $275(5.4)$ & $284(5.7)$ & \\
\hline
\end{tabular}

$\chi^{2}$ : Chi-square test of independence between trauma type and gender

$* \mathrm{p}<0.05, * * \mathrm{p}<0.01, * * * \mathrm{p}<0.001$

Table 2 Fit indices of the latent class analysis of trauma

\begin{tabular}{lcccccc}
\hline \multicolumn{1}{c}{ Model } & $\begin{array}{c}\text { Log } \\
\text { likelihood }\end{array}$ & AIC & BIC & ssaBIC & LMR & Entropy \\
\hline 2 class & -41096 & 82267 & 82534 & 82417 & 4265 & 0.74 \\
& & & & & 0.00 & 0.76 \\
3 class & -40860 & 81831 & 82236 & 82058 & 471 & 0.00
\end{tabular}




\begin{tabular}{lcccccc}
$\mathbf{4}$ class & $\mathbf{- 4 0 7 2 3}$ & $\mathbf{8 1 5 9 6}$ & $\mathbf{8 2 1 3 8}$ & $\mathbf{8 1 8 9 9}$ & $\mathbf{2 7 2}$ & $\mathbf{0 . 7 5}$ \\
& & & & & $\mathbf{0 . 0 1}$ & 0.63 \\
$\mathbf{5}$ class & -40666 & 81520 & 82199 & 81900 & 114 & 0.72 \\
\multirow{2}{*}{ c class } & -40613 & 81453 & 82269 & 81910 & 104 & 0.64 \\
\hline
\end{tabular}


Table 3 Demographic variables predicting latent class membership

\begin{tabular}{|c|c|c|c|}
\hline $\begin{array}{l}\text { Predictor } \\
\text { (Baseline \%) }\end{array}$ & $\begin{array}{c}\text { Class1 } \\
\text { High risk } \\
(N=132) \\
\text { OR } \\
(95 \% C I) \\
\text { Class \% } \\
\end{array}$ & $\begin{array}{c}\text { Class2 } \\
\text { Sexual assault risk } \\
(N=467) \\
\text { OR } \\
(95 \% C I) \\
\text { Class \% } \\
\end{array}$ & $\begin{array}{c}\text { Class3 } \\
\text { Non-sexual risk } \\
(N=1579) \\
\text { OR } \\
(95 \% C I) \\
\text { Class \% } \\
\end{array}$ \\
\hline \multicolumn{4}{|l|}{ Gender } \\
\hline $\begin{array}{c}\text { Female } \\
(51.6)\end{array}$ & $\begin{array}{c}2.48^{* * *} \\
(1.37-4.46) \\
71.2\end{array}$ & $\begin{array}{c}8.15^{* * *} \\
(5.32-12.48) \\
88.5\end{array}$ & $\begin{array}{c}0.58^{* * *} \\
(0.48-0.69) \\
35.9\end{array}$ \\
\hline Male & $b$ & $b$ & $b$ \\
\hline \multicolumn{4}{|l|}{ Race } \\
\hline $\begin{array}{c}\text { Hispanic } \\
(\mathbf{1 7 . 8 5})\end{array}$ & $\begin{array}{c}1.69 \\
(0.84-3.40) \\
31.1\end{array}$ & $\begin{array}{c}1.26 \\
(0.83-1.93) \\
21.2\end{array}$ & $\begin{array}{c}1.71^{* * *} \\
(1.39-2.16) \\
22.7\end{array}$ \\
\hline $\begin{array}{l}\text { Black } \\
\text { (17.8) }\end{array}$ & $\begin{array}{c}0.77 \\
(0.37-1.57) \\
18.9\end{array}$ & $\begin{array}{c}0.69^{*} \\
(0.48-0.99) \\
21.0\end{array}$ & $\begin{array}{c}1.73^{* * *} \\
(1.39-2.16) \\
26.4\end{array}$ \\
\hline $\begin{array}{l}\text { Other } \\
(6.0)\end{array}$ & $\begin{array}{c}0.83 \\
(0.38-1.83) \\
11.4\end{array}$ & $\begin{array}{c}1.08 \\
(0.62-1.89) \\
6.2\end{array}$ & $\begin{array}{c}1.56^{*} \\
(1.04-2.36) \\
6.3\end{array}$ \\
\hline $\begin{array}{c}\text { White } \\
\text { Living Arrangement }\end{array}$ & \multicolumn{2}{|c|}{ Living Arrangements } & $b$ \\
\hline $\begin{array}{c}0 \text { parents } \\
(7.2)\end{array}$ & $\begin{array}{c}14.49^{* * *} \\
(6.28-33.39) \\
29.5\end{array}$ & $\begin{array}{c}10.07^{* * *} \\
(6.50-15.62) \\
22.3\end{array}$ & $\begin{array}{c}3.29^{* * *} \\
(2.55-4.25) \\
16.4\end{array}$ \\
\hline $\begin{array}{l}1 \text { parent } \\
(35.0)\end{array}$ & $\begin{array}{c}4.43^{* * *} \\
(2.03-9.66) \\
53.8\end{array}$ & $\begin{array}{c}3.34^{* * *} \\
(2.38-4.70) \\
49.6\end{array}$ & $\begin{array}{c}1.72^{* * *} \\
(1.42-2.09) \\
45.4\end{array}$ \\
\hline 2 parents & $b$ & $b$ & $b$ \\
\hline
\end{tabular}

Each trauma risk class is compared to the Baseline (low risk class, $N=7945$ ) with $b$ as the comparison within variables

$* \mathrm{p}<0.05, * * \mathrm{p}<0.01, * * * \mathrm{p}<0.001$ 
Table 4 Clinical disorders (lifetime diagnoses) predicted by class membership

\begin{tabular}{|c|c|c|c|c|c|c|}
\hline & $\begin{array}{c}\text { Alcohol } \\
\text { Abuse }\end{array}$ & $\begin{array}{l}\text { Drug } \\
\text { Abuse }\end{array}$ & Dysthymia & $\begin{array}{c}\text { Major } \\
\text { Depressive } \\
\text { Episode }\end{array}$ & $\begin{array}{c}\text { Generalised } \\
\text { Anxiety } \\
\text { Disorder }\end{array}$ & $\begin{array}{l}\text { Post-traumatic } \\
\text { Stress Disorder }\end{array}$ \\
\hline & $\begin{array}{c}\text { OR } \\
(95 \% \mathrm{CI}) \\
\text { Class \% } \\
\\
\text { (Baseline: } \\
\mathbf{3 . 9 \%} \text { ) } \\
\end{array}$ & $\begin{array}{c}\text { OR } \\
(95 \% \mathrm{CI}) \\
\text { Class \% } \\
\text { (Baseline: } 4.9 \%)\end{array}$ & $\begin{array}{c}\text { OR } \\
(95 \% \mathrm{CI}) \\
\text { Class \% } \\
\\
\text { (Baseline: } \\
\mathbf{1 . 8 \% )} \\
\end{array}$ & $\begin{array}{c}\text { OR } \\
(95 \% \mathrm{CI}) \\
\text { Class \% } \\
\\
\text { (Baseline: } \\
\text { 9.3\%) } \\
\end{array}$ & $\begin{array}{c}\text { OR } \\
(95 \% \mathrm{CI}) \\
\text { Class \% } \\
\\
\text { (Baseline: } \\
\mathbf{2 . 1 \%} \% \\
\end{array}$ & $\begin{array}{c}\text { OR } \\
(95 \% \mathrm{CI}) \\
\text { Class \% } \\
\\
\text { (Baseline: } \\
\mathbf{1 . 4 \% )} \\
\end{array}$ \\
\hline $\begin{array}{c}\text { Class 1 } \\
\text { High risk } \\
(N=132)\end{array}$ & $\begin{array}{c}14.18^{* * *} \\
(7.62-26.38) \\
34.1\end{array}$ & $\begin{array}{c}12.69^{* * *} \\
(7.06-22.80) \\
43.2\end{array}$ & $\begin{array}{c}11.33^{* * *} \\
(5.97-21.50) \\
23.5\end{array}$ & $\begin{array}{c}11.49^{* * *} \\
(6.57-20.07) \\
53.0\end{array}$ & $\begin{array}{c}7.58^{* * *} \\
(3.69-15.58) \\
15.9\end{array}$ & $\begin{array}{c}39.58^{* * *} \\
(20.30-77.16) \\
34.1\end{array}$ \\
\hline $\begin{array}{c}\text { Class } 2 \\
\text { Sexual } \\
\text { assault risk } \\
(N=467)\end{array}$ & $\begin{array}{c}4.76^{* * *} \\
(3.12-7.27) \\
14.2\end{array}$ & $\begin{array}{c}6.43^{* * *} \\
(4.33-9.54) \\
19.2\end{array}$ & $\begin{array}{c}9.99^{* * *} \\
(6.22-16.04) \\
13.1\end{array}$ & $\begin{array}{c}7.62^{* * *} \\
(5.57-10.42) \\
36.9\end{array}$ & $\begin{array}{c}3.72^{* * *} \\
(2.28-6.06) \\
10.0\end{array}$ & $\begin{array}{c}26.24^{* * *} \\
(17.12-40.20) \\
25.7\end{array}$ \\
\hline $\begin{array}{c}\text { Class } 3 \\
\text { Non-sexual } \\
\text { risk } \\
(N=1579)\end{array}$ & $\begin{array}{c}4.62^{* * *} \\
(3.54-6.01) \\
15.6\end{array}$ & $\begin{array}{c}4.65^{* * *} \\
(3.68-5.88) \\
20.9\end{array}$ & $\begin{array}{c}4.24^{* * *} \\
(2.84-6.34) \\
6.2\end{array}$ & $\begin{array}{c}2.93^{* * *} \\
(2.36-3.64) \\
22.5\end{array}$ & $\begin{array}{c}2.47^{* * *} \\
(1.53-3.99) \\
4.2\end{array}$ & $\begin{array}{c}6.80^{* * *} \\
(4.40-10.50) \\
7.1\end{array}$ \\
\hline
\end{tabular}

Baseline: Low risk class $(N=7945)$

$* \mathrm{P}<0.05 ; * * \mathrm{P}<0.01 ; * * * \mathrm{P}<0.001$ 
Table 5 Comorbidity of clinical disorders (lifetime diagnoses) predicted by class membership

\begin{tabular}{|c|c|c|c|c|}
\hline $\begin{array}{r}\text { Comorbidity } \\
\text { of Disorder } \\
\text { Type }\end{array}$ & $\begin{array}{c}\text { Substance Use } \\
\text { \& Mood }\end{array}$ & $\begin{array}{c}\text { Substance Use } \\
\text { \& Anxiety }\end{array}$ & $\begin{array}{l}\text { Mood \& } \\
\text { Anxiety }\end{array}$ & $\begin{array}{c}\text { Substance Use } \\
\text { \& Mood \& } \\
\text { Anxiety }\end{array}$ \\
\hline & $\begin{array}{c}\text { OR } \\
(95 \% \mathrm{CI})\end{array}$ & $\begin{array}{c}\text { OR } \\
(95 \% \mathrm{CI})\end{array}$ & $\begin{array}{c}\text { OR } \\
(95 \% \mathrm{CI})\end{array}$ & $\begin{array}{c}\text { OR } \\
(95 \% \mathrm{CI})\end{array}$ \\
\hline & Class \% & Class \% & Class $\%$ & Class $\%$ \\
\hline & (Baseline: $1.4 \%$ ) & (Baseline: $0.5 \%$ ) & (Baseline: 1.4\%) & (Baseline: $0.2 \%$ ) \\
\hline $\begin{array}{c}\text { Class } 1 \\
\text { High risk } \\
(N=132)\end{array}$ & $\begin{array}{c}7.55^{* * *} \\
(2.53-22.51) \\
28.0\end{array}$ & $\begin{array}{c}23.52^{* * *} \\
(7.12-77.62) \\
25.0\end{array}$ & $\begin{array}{c}9.99^{* * *} \\
(4.40-22.67) \\
31.8\end{array}$ & $\begin{array}{c}109.74^{* * *} \\
(42.31-284.63) \\
18.2\end{array}$ \\
\hline $\begin{array}{c}\text { Class } 2 \\
\text { Sexual } \\
\text { assault risk } \\
(N=467)\end{array}$ & $\begin{array}{c}8.98^{* * *} \\
(4.24-19.04) \\
10.8\end{array}$ & $\begin{array}{c}21.23^{* * *} \\
(8.37-53.88) \\
8.4\end{array}$ & $\begin{array}{c}9.97^{* * *} \\
(6.09-16.33) \\
16.6\end{array}$ & $\begin{array}{c}29.90^{* * *} \\
(13.23-67.58) \\
4.9\end{array}$ \\
\hline $\begin{array}{c}\text { Class } 3 \\
\text { Non-sexual } \\
\text { risk } \\
(N=1579)\end{array}$ & $\begin{array}{c}5.22^{* * *} \\
(3.42-7.96) \\
8.1\end{array}$ & $\begin{array}{c}9.94^{* * *} \\
(3.91-25.27) \\
3.7\end{array}$ & $\begin{array}{c}4.12^{* * *} \\
(2.39-7.09) \\
5.7\end{array}$ & $\begin{array}{c}8.11^{* * *} \\
(3.54-18.58) \\
2.1\end{array}$ \\
\hline
\end{tabular}

Baseline: Low risk class $(N=7945)$

$* \mathrm{P}<0.05 ; * * \mathrm{P}<0.01 ; * * * \mathrm{P}<0.001$ 